\title{
BETA2 and Pancreatic Islet Development
}

\author{
Khol Chu, Eric Nemoz-Gaillard, and Ming-Jer Tsaj \\ Department of Molecular and Cellular Biology, Baylor College of Medicine, \\ I Baylor Plaza, Houston, Texas 77030
}

\begin{abstract}
The pancreas is essential for digestion and glucose homeostasis. Diseases associated with the pancreas (e.g., pancreatitis, pancreatic cancer, diabetes) are generally debilitating for the patient. Diabetes is particularly prominent in the United States, affecting nearly 6 percent of the population, with associated annual health costs in the billions of dollars. Pancreas development is a complex process that requires the timely expression of numerous factors. Among them, a basic Helix-LoopHelix factor, BETA2, was shown to be important for terminal differentiation of islet cells including insulin- and glucagon-producing cells. Expression studies demonstrated the presence of BETA2 in islet cells and specific neurons. Targeted deletion of the BETA2 gene in mice revealed its significance in pancreas development. In addition, BETA2 is important in granule cell development of the hippocampus and cerebellum. This chapter will focus on the role of BETA2 in pancreas physiology, neuronal development, and its molecular biology.
\end{abstract}

\section{Introduction}

According to the American Diabetes Association (ADA), 15.7 million Americans (10.3 million diagnosed and 5.4 million undiagnosed), representing 5.9 percent of the U.S. population, suffer from diabetes. Diabetes mellitus, whether type 1 (insulin-dependent diabetes mellitus (IDDM), 5-10 percent of diabetes) or type 2 (non-insulin-dependent diabetes mellitus (NIDDM), 90-95 percent of diabetes), results from an impaired glucose homeostasis by the hormone insulin. In the former, a complex autoimmune process leads to the loss of insulin-secreting cells of the pancreas, while the latter is characterized by a failure to compensate for peripheral insulin resistance.

An increasing number of factors have been implicated in the etiology of diabetes, pointing to both environmental and genetic determinants in the development of this disease. Over the past few years, the efficiency of modern molecular biology techniques, with the generation and analysis of numerous transgenic and knockout animals, provoked an explosion of the number of publications on the development of the pancreas and, more specifically, of islet cells. The results obtained from these studies have revealed some of the complex mechanisms 
governing the ontogeny of pancreatic endocrine cells. Indeed, an elaborate developmental program was expected in order to maintain the integrity and functionality of the pancreas.

Among the important molecular factors involved in the proper formation of the pancreas, our group described the transcription factor BETA2 to be critical for the terminal differentiation of pancreatic islets (Naya et al., 1995,1997). In addition, BETA2 plays a significant role in the development of various structures in the nervous system (Lee et al., 1995; Liu et al., 2000a,2000b; Miyata et al., 1999).

This chapter will focus mainly on the role of BETA2 in pancreas development and its molecular biology. Its function outside the pancreas also is described, to profile the multifaceted role of this differentiation factor.

\section{A. PANCREAS}

The mature pancreas is comprised of three main type of cells: duct epithelium, endocrine, and exocrine cells (Pictet et al., 1972; Slack, 1995). The exocrine cells, which represent the major cell type in the pancreas, secrete digestive enzymes into the duodenum through a branched ductal system. In contrast, endocrine cells represent 1 to 2 percent of the mature pancreas mass. These cells are arranged as compact, spheroidal clusters of hormone-producing cells, dispersed throughout the pancreas, named the islets of Langerhans. An adult islet is composed of four major cell types $-\alpha, \beta, \delta$, and pancreatic polypeptide (PP) cells - that synthesize glucagon, insulin, somatostatin, and pancreatic polypeptide, respectively. In addition to the glandular component, islets have a rich blood supply through a sophisticated, intra-islet portal system. Importantly, it appears that the directional flow in the islet portal system may be a major determinant of $\beta$-cell function and therefore is pertinent to subsequent functioning of the organ.

In humans, the pancreas is a well-defined, elongated, triangular organ of 15-25 centimeters weighing about 70-100 grams. In rodents, the shape of the pancreas is less well defined, appearing as a loose mass of tissue attached to the stomach and small intestine. In rodents, the islets are normally rounded, with a central core of $\beta$ cells surrounded by a mantle, primarily composed of glucagon cells intermingled with $\delta$ and PP cells. In humans, islets are lobulated and the segregation of $\beta$ cells vs. $\alpha, \delta$, and PP cells is not as well defined.

\section{B. PANCREAS DEVELOPMENT}

Despite some discrepancies between species in the overall structural or substructural pancreatic organization, the developmental program of the pancreas is essentially equivalent in mammals and, so far, is known to involve the same molecular components (Grapin-Botton and Melton, 2000; Kim et al., 1997; Wells 
and Melton, 1999). Upon the appropriate inductive signals, two pancreatic anlaga bud from the gut endoderm into the surrounding splanchnic mesoderm (Pictet et al., 1972). As these buds grow, they rapidly form new protrusions, leading to a highly branched structure. These two primitive outgrowths develop independently, forming both endocrine and exocrine tissues, and finally merge to form the pancreas. In the developing pancreas, a subset of cells adjacent to the nascent pancreatic duct has been identified as progenitor cells for the pancreatic islets. These progenitor cells actively proliferate, then differentiate through a series of maturation steps as they migrate away from the duct to finally aggregate into mature, properly organized islets. The identity of the endocrine progenitor cells remains elusive and is the object of active research by both academic and pharmaceutical scientists. Overall, the development of the pancreas appears as a complex process involving many factors whose identities and functions are now being uncovered.

Several transcription factors from the homeodomain, basic Helix-Loop-Helix (bHLH), and winged-helix families have been identified to play a role at various stages or decision branchpoints of pancreas development. These include Isletl, PDX1, Pax4, Pax6, Nkx2.2, Nkx6.1, HB9, and hepatocyte nuclear factor (HNF)6 in the homeodomain family (Ahlgren et al., 1996,1997; Gannon et al., 2000; Harrison et al., 1999; Jacquemin et al., 2000; Jonsson et al., 1994; Li et al., 1999; Offield et al., 1996; Sosa-Pineda et al., 1997; St-Onge et al., 1997); HNF3 $\alpha$ and HNF3 $\beta$ in the winged-helix family (Ang and Rossant, 1994; Kaestner et al., 1999; Weinstein et al., 1994); and BETA2, Neurogenin3 (NGN3), p48, and hairy and enhancer of split l (HES1) in the bHLH family (Gradwohl et al, 2000; Ishibashi et al., 1995; Jensen et al., 2000b; Krapp et al., 1998; Naya et al., 1995,1997). Among these, PDX1, NGN3, and HES1 seem to interact, physically or functionally, with BETA2, in a direct or indirect manner. Since it is beyond the scope of this chapter to discuss or dissect the role of other transcription factors involved in pancreas development, readers are invited to consult recent reviews (Bramblett et al., 2000; Edlund, 1998, 1999).

\section{PDXI}

PDX1 - a homeobox gene also known as IPF-1, STF-1, IDX-1, and $\mathrm{XIHbox} 8$ - was shown to be involved in islet hormone gene transcription and expressed in pancreatic tissue during development and in the adult (Guz et al., 1995; Leonard et al., 1993; Miller et al., 1994; Peshavaria et al., 1994; Serup et al., 1995). During embryonic development, PDX1 is expressed in a domain that includes the pancreatic buds and expands from the antral part of the stomach to the proximal duodenum (Ahlgren et al., 1996; Guz et al., 1995; Jonsson et al., 1995; Offield et al., 1996; Serup et al., 1995). As differentiation proceeds, PDX1 expression is progressively restricted to $\beta$ cells and some $\delta$ cells. In mice and 
humans harboring a defective mutation of PDX1, the pancreas is absent (Jonsson et al., 1994; Offield et al., 1996; Stoffers et al., 1999). This dramatic phenotype suggests that PDX1 is required for the proliferation and differentiation of the presumptive pancreatic epithelium from the foregut. Studies in $\mathrm{PDXN}^{\%}$ mice indicated that both insulin- and glucagon-producing cells are present in the pancreatic buds, suggesting that regulation of the insulin and glucagon genes is complex and requires many factors besides PDX1 (Offield et al., 1996). In order to study the role of PDX1 in adult mice, the PDX1 gene was specifically disrupted in $\beta$ cells by using the CRE-LoxP system under the control of the insulin promoter (Ahlgren et al., 1998). PDX1 was shown to be required for the maintenance of $\beta$ cells and to positively regulate insulin expression (Ahlgren et al., 1998). Overall, in addition to its early involvement in the patterning of the pancreatic primordia, PDX1 appears to participate in the regulation of insulin gene expression in mature pancreatic $\beta$ cells.

\section{Neurogenin 3}

The neurogenins (NGNs) are bHLHs of the Atonal subfamily, an important pro-neural gene in Drosophila. Consistent with such a role, targeted ablation of NGN1 or NGN2 results in the absence of specific neurons (Fode et al., 1998,2000; Ma et al., 1996,1998,1999; Perez et al., 1999). NGN3 - also named Math4B or Relax - is specifically expressed during embryogenesis in the pancreas, the developing neural tube, and the hypothalamus (Ma et al., 1996). In the developing pancreas, NGN3 expression can be observed very early in a speckled pattern (e9.0 in the mouse, i.e., when pancreatic buds are starting to form). These cells have been considered to represent pancreatic islet progenitors (Gradwohl et al., 2000; Schwitzgebel et al., 2000). Consistent with this idea, NGN3 expression is transient in the developing pancreas; increasing levels of NGN3 are observed from e9.5 to e15.5 and decline thereafter. Interestingly, BETA2 expression is superficially similar to NGN3, suggesting a possible regulation of BETA2 by NGN3 (Figure 1) (Huang et al., 2000). Indeed, NGN3 expression is restricted to a subset of proliferating cells associated with the nascent duct epithelium and mostly overlaps with those of the early islet differentiation factors PDX1, Nkx6.1, and Nkx2.2 (Jensen et al, 2000a; Schwitzgebel et al., 2000). Interestingly, targeted disruption of the NGN3 gene results in a total loss of pancreatic endocrine cells, highlighting the crucial role played by NGN3 in pancreatic islet cell formation (Gradwohl et al., 2000). Furthermore, in a gain-of-function study, NGN3 induced premature differentiation of pancreatic precursor cells into endocrine cells, to the detriment of the exocrine tissue when ectopically expressed in the pancreatic bud under control of the PDX1 promoter (Apelqvist et al., 1999; Schwitzgebel et al., 2000). These results are consistent with the pro-endocrine role of the NGN3 gene (Figure 1) and are compatible with the pro-neural function of Atonal in Drosophila. 


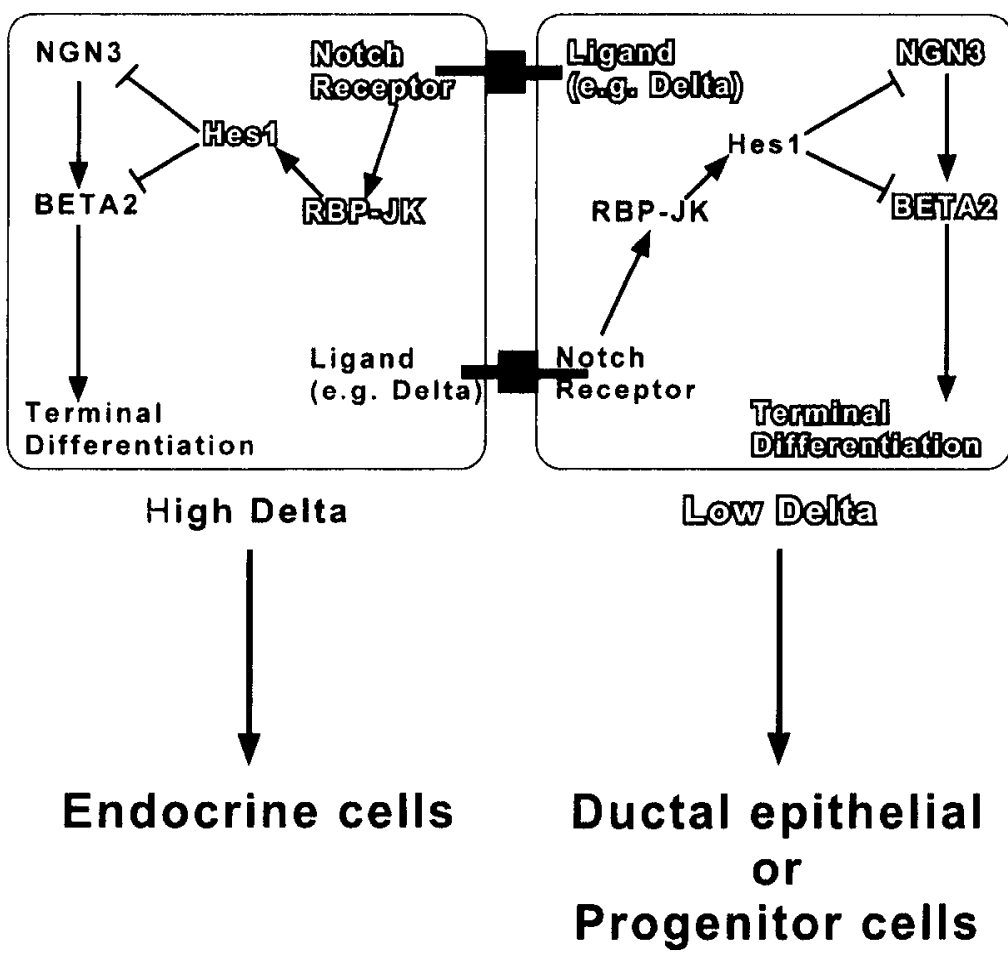

FIG. 1. Lateral inhibition. In lateral inhibition, signaling requires direct cell-cell contact. Notch signaling is pivotal for lateral inhibition to operate. In a homogenous cell population, there may be small variation in the concentration of ligands and receptors among cells. The initial changes are amplified, so that the cell adopting one fate (e.g., endocrine) expresses high levels of ligand and low levels of receptor, while the neighboring cell that takes another fate (e.g., ductal epithelial or progenitor) expresses low levels of ligand and high levels of receptor.

\section{HESI}

Hairy, otherwise known as enhancer of split-1 (HES1), is a bHLH protein that encodes a transcriptional repressor, which generally antagonizes positive bHLH proteins such as Mash1 (Guillemot, 1999). HES1 is important for normal embryonic development. Deletion of the HES1 locus in mice results in embryonic death (Guillemot, 1999; Ishibashi et al., 1995). Many defects are observed and include a small pancreas and the lack of brain, eyes, and thymus. The neuronal phenotype was attributed to a depletion of precursor cells due to premature differentiation. The proneural gene Mash 1 was upregulated in neuronal precursor cells, which suggests a potential role of HESl in the control of positive bHLHs such as Mash1. In analogy to the phenotype observed in the brain, the develop- 
ment of the pancreas is pcrturbed and premature differentiation of endocrine precursor cells also is observed (Jensen et al., 2000b). HES1 is expressed in PDX1-expressing ductal epithelial cells at e12.5 and also in the adjacent mesenchymal cells (Jensen et al., 2000b). In HES1 $1^{-/}$embryos, the expression of NGN3 and BETA2 is upregulated in endoderm-derived tissues such as the stomach and intestine. Similar studies were not performed with pancreatic tissues due to the severe disruption of normal pancreatic structure in HES1\% embryos. Nevertheless, the HES1 pancreatic phenotype is likely to involve the NGN3-BETA2 pathway (Figure 1), as will be discussed.

HES- 1 is an important mediator of the Notch signaling pathway, which plays a pivotal role in lateral inhibition, a mechanism mediating asymmetric signaling between adjacent cells (Jarriault et al., 1995,1998). The lateral inhibition model supposes, in the simplest example, a group of equivalent cells expressing both the receptor Notch and the ligand Delta. Notch-Delta interaction leads to Notch activation by its proteolytic cleavage and release of the Notch intracellular domain, which associates with the DNA binding protein RBP-JK, and the transcription of genes such as HES1. HES1 then represses downstream target genes such as the neurogenins as well as the Notch ligand Delta. Consequently, due to normal variation in expression among cells, a cell that produces more ligand will cause its neighbors to produce less. This enables the cell to increase its ligand production even further because it receives a weakened inhibitory signal from its neighbors. The effect of this feedback loop is to drive neighboring cells into distinct cell fates; any initial difference between them is intensified and maintained.

In the pancreas, most epithelial cells express both Notch1 and Notch2, while Notch 3 is detected in endothelial cells (Apelqvist et al., 1999; Jensen et al., 2000b; Lammert et al., 2000). The ligand Delta-like I is detected in scattered ductal epithelial cells, which suggests a potential role for it as a determinant of cell fate (Lammert et al, 2000). Other experimental models have implicated the lateral inhibition mechanism in the pancreas (Figure 1). Indeed, knockout of important players of the Notch signaling pathway - such as the Delta-like gene I, the intracellular mediator RBP-JK, and the repressor HES1 - will lead to an accelerated differentiation of pancreatic endocrine cells and the subsequent depletion of the pancreatic precursor pool (Apelqvist et al., 1999; Jensen et al., 2000b). In addition, expression of a dominant-negative form of Notch3 in ductal epithelial cells showed a similar premature differentiation phenotype (Apelqvist et al., 1999). This phenotype is associated with an increase of the expression of positive regulators of endocrine cell lineage such as NGN3 and BETA2, suggesting that the overexpression of NGN3 and BETA2 should result in a similar phenotype. Indeed, overexpression of the activators NGN3 and BETA2 in ductal epithelial cells induces premature endocrine differentiation by depleting the initial pool of endocrine cell precursors (Apelqvist et al., 1999; Schwitzgebel et al., 2000). 
Taken together, these results indicate an important role for the Notch signaling pathway in pancreatic development.

\section{Molecular Biology of BETA2}

\section{A. CLONING OF BETA2}

Most of the transcription factors discovered to play a key role during pancreatic development have been initially characterized as factors involved in the regulation of pancreatic hormone gene expression. This reverse genetic approach has been used successfully as a paradigm to clone transcription factors acting in the pancreatic differentiation process (e.g., BETA2) by our group, after many years of intense classical molecular biology research. The insulin promoter RIPE3 DNA element was identified by us and others as an important DNA element for insulin gene transcription (Crowe et al., 1988; Crowe and Tsai, 1989; Hwung et al., 1990; Robinson et al., 1994; Shieh and Tsai, 1991). The RIPE3 element consists of two cooperative subelements, RIPE3a and RIPE3b. Further examination of the RIPE3a sequence revealed a close resemblance to the consensus DNA element E-box, a known target of the bHLH family of transcription factors. In addition, RIPE3a binding activity is detected by gel-shift assays in insulin-expressing but not in nonexpressing cell lines (e.g., the hamster insulinoma cell line HIT vs. the kidney-derived cell line BHK) (Shieh and Tsai, 1991). Thus, the factor that binds to the RIPE3a element appears to be present only in insulin-producing lines. Taken together, these observations indicated that a tissue-restricted transcription factor of the bHLH family was a likely candidate for the RIPE3a binding activity.

The bHLH family of transcription factors is a very-well-conserved protein family with members present from yeast to higher eukaryotes. Most bHLH proteins bind to the consensus sequence CANNTG (Blackwell et al., 1993; Blackwell and Weintraub, 1990; Murre et al., 1989a). Three-dimensional studies of bHLH proteins have revealed the presence of two conserved helices separated by a loop or spacer region (Ellenberger et al., 1994; Ferre-D'Amare et al., 1993,1994; Ma et al., 1994). The basic region of bHLH factors is located N-terminal of the first helix and is required to interact with the DNA (Murre et al., 1989b; Voronova and Baltimore, 1990). The dimerization interface involves both helices 1 and 2 and is stabilized by van der Waals interactions and hydrogen bonds.

The bHLH family of transcription factors can be divided into three classes. The first, class A bHLHs, generally are characterized by an ubiquitous tissue distribution and an ability to bind DNA as homodimers or heterodimers with class $B$ members. The class B factors are tissue specific and bind DNA as a heterodimer with a class $A$ member. The class $C$ proteins are characterized by a leucine zipper motif located C-terminal to the bHLH. The latter class seems to dimerize via the 
leucine zipper and thus does not interact with either class A or B. The tissue-restricted class B bHLHs are believed to play important functions as developmental regulators. Hence, they are involved in the morphogenesis of various organs, ranging from muscle formation, with the $\mathrm{MyoD}$ family, to neurogenesis, with the Atonal and Achaete-Scute family.

Taking advantage of the requirement of class B or tissue-specific bHLH factors to dimerize with class A members, a modified yeast two-hybrid system was used to clone the RIPE3a binding activity (Naya et al., 1995). The ubiquitous bHLH E47 without the activation domain was chosen as the bait, since it was previously shown to be present in the RIPE3a complex. The library was derived from the insulinoma HIT cell line, where the RIPE3a activity can be detected. A clone was selected and named BETA2. The same protein was cloned as an interacting partner of the ubiquitous Drosophila bHLH Daughterless using a very similar yeast-based assay (Lee et al., 1995). This clone was termed NeuroD for its ability to induce neuronal differentiation when ectopically expressed in ectodermal cells. For the purpose of simplicity, the BETA2 nomenclature is used here, since this review is focused on the pancreas.

\section{B. BETA2}

As deduced from the cloned cDNA sequence, the hamster BETA2 encodes a $42 \mathrm{kD}$-protein of 355 amino acids with a bHLH domain located between residues 100 to 155 . In addition to its restricted expression pattern (see below), the presence of a characteristic tyrosine in the second helix indicates that it belongs to the class B subfamily. Sequence alignment of BETA2 proteins from different species reveals an overall strong homology between mouse, rat, human, chicken, frog, and zebrafish protein sequences (Figure 2). BETA2 is highly homologous to NeuroD-related factor (NDRF2), Nex1/Math2, and NGN1/NDF3 (Figure 3). Interestingly, these all have a very-well-conserved loop sequence (CYSKTQ) that could potentially define them as a subgroup (Figure 3 ).

Like most class B bHLHs, BETA2 has no DNA binding capacity by itself but is strongly stimulated by heterodimerization with class A bHLH proteins (e.g., E47). In the insulin promoter, the RIPE3 mini-enhancer is composed of binding sites for multiple proteins, including BETA2 and PDX1. Synergistic activation of this mini-enhancer is observed between BETA2 and PDX1. The molecular mechanism for this effect recently was reported and involved the direct interaction of BETA2 and PDX1 via the bHLH domain of BETA2 and the homeodomain of PDX1 (Glick et al., 2000; Ohneda et al., 2000). In addition, PDX1 is able to interact with other bHLH proteins, including the ubiquitous E47 (Ohneda et al., 2000; Poulin et al., 2000). This interaction does not result in cooperative DNA binding between bHLH proteins and PDX1 but rather in a clustering of multiple 
transcriptional activators, which enhance transcription by intcracting with coactivators and the basal transcriptional machinery.

Indeed, BETA2's transactivation potential is stimulated by the presence of the coactivator p300 or CREB binding protein (CBP) (Mutoh et al., 1998; Qiu et al., 1998; Sharma et al., 1999). Two activation domains (AD1 and AD2) were identified C-terminal of the bHLH domain (Figure 4). The AD1 located within amino acids 189 to 299 is more active than the AD2 (aa 300 to 355). The two ADs do not appear to synergize with each other; rather, they seem to act independently. The activity of both ADs correlates with their ability to interact with the coactivator $\mathrm{p} 300$. The bHLH domain of BETA2 also was reported to interact with $\mathrm{p} 300$, while no other region of BETA2 - including the C-terminal region — was able to interact with $\mathrm{p} 300$ in this study (Mutoh et al., 1998). It is interesting to point out that the myogenic bHLH MyoD is able to interact with p300 via its bHLH domain and its N-terminal activation domain (Puri et al., 1997; Sartorelli et al., 1999). Thus, it is possible that, depending on the system or context used, different interaction domains of BETA2 are important. Additionally, the transcriptional ability of BETA2 may be enhanced by its heterodimerization with a partner able to interact with the p300/CBP family of coactivators. Finally, most of the activation studies have been performed using transient transfection assays and artificially high amounts of bHLH or Gal4 fusion proteins and may not entirely recapitulate the in vivo environment. This is reflected by some lack of consistency in the reported data between various groups and further analysis is required to clarify the discrepancies.

\section{Physiological Functions of BETA2}

\section{A. BETA2 AND PANCREAS}

BETA2 is expressed in both the developing and adult pancreas. In mature islet, BETA2 is expressed in all endocrine cells, making the name BETA2 somewhat misleading. The exact function of BETA2 in the mature islet is unknown. BETA2 is involved in regulation of insulin and glucagon genes. However, this function does not appear to be a major one, since mutant mice lacking the BETA2 gene still are able to express insulin and glucagon in the pancreas (see below). In $\delta$ and PP cells, the role of BETA2 remains unknown. During embryonic development, the expression pattern of BETA2 is best visualized by X-gal staining as an assay for the enzymatic activity of $\beta$-galactosidase resulting from the replacement of the coding region of the murine BETA2 gene by the bacterial LacZ gene. When such an approach is used, the activity of the endogenous BETA2 gene can be monitored in heterozygous mice. To the best of our knowledge, the staining pattern detected by X-gal appears to reflect the endogenous BETA2 expression 
$\mathrm{MmBETA} 2$ $\mathrm{R} \cap \mathrm{BETA} 2$ C gBETA 2 H S B E T A 2 G g B T A 2 XIBEA 2 D $\triangle B E T A 2$ consensus

MmBETA 2 R n B T T 2 C gBETA 2 H $\triangle$ BETA 2 G gBET 2 $\mathrm{X} 1 \mathrm{BETA} 2$ D $~ B E T A 2$ consensus

M B B TA 2 R I B T A 2 C gBETA 2

HSBETA 2 G gBETA 2 X 1 B E T A 2

D $\triangle$ BETA 2

consensus

$\mathrm{MmBETA} 2$ RnB T A 2 C gBETA 2 H $\triangle B E T A 2$ G g B T T 2 $X 1$ BETA2 D $\triangle B E T A 2$ consensu
MTKSYSESGLMGEP QPQGPPSWTDECLSSQDEEHEADKK-GDELEAMN- - A EDSLK - - N MTKSYSESGLMGEP OPOGP P SWTDECLSSQDEEHEADKK-EDELEAMN- - A E EDS LR - - N MTKSYSESGLUGEPQPQGP SWTDECLSSQDEDHEADKK-EDELEAMN- - A E EDSLR- - N MTKSYSES CLMGBPQPQ GP PSWTDECZSSQDEEHEADKK-EDDLEAMN- - A EDSLR- -N MTKSYSESGPAGEP QAQAP PGWA A GCLSP PADGPEADKK-EEDLEALHGEAEEDALR- - N MTKSYGENGLILAETP-GCRGWVDECLSSQDEN-DLEKK-EGELMKED- - DEDSLNHHW

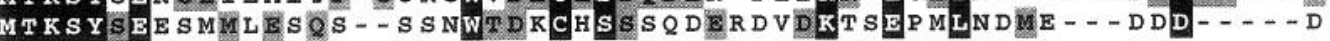

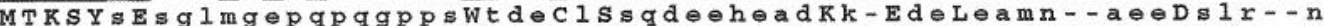

Basic

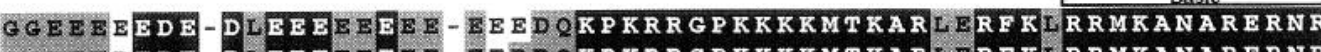
GGEEEDEDE-DLEEEEEEIE-EEDD OKPKRRGPKKKKMTKARLERFKLRRMKANARERNR C.CDEEDEDE-DLEEEDEEE E-B-DDQKPKRRGPKKKKMTKARLERFKLRRMKANARERNR GGEB BDEDE-DLEEEEEEE E- EDDDQKPKRRGPKKKKMTKARLERFKLRRMKANARERNR GEERDEEDELDEEEEEEEE E-EDDEQKPKRRGPKKKKMTKARLERFKLRRMKANARERNR GEENEEEDEGDEEEEDDEDDDEDDDQKPKRRGPKKKKMTKARVERFKVRRMKANARERNR A GLNRLEDE-DDEEEEEEEE-DGDDTKPKRRGPKKKKMTKARMQRFKMRRMKANARERNR

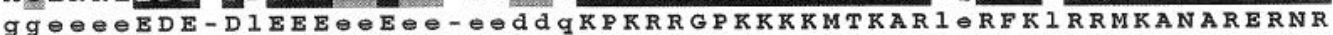
g gee e E DE-DIEEEe E Loop Helix

MHGLNAALDNLRKVVPCYSKTQKLSKIETLRLAKNYIWALSEILRSGKSPDLVSFVOTLC IH GLNAALDNLRKVVPCYSKTQKLSKIETLRLAKNYIVALSEILRSGKSPDLVSFVQTLC MH GLNAALDNLRKVVPCYSKTQKLSKIETLRLAKNYIWALSEILRSGKSPDLVSFVQTLC MH GLNAALDNLRKVVPCY STQRLSKIETLRLAKNYIWALSEILRSGKSPDLVSFVQTLC MH GLNAALDNLRKVVPCYSKTQKLSKIETLRLAKNYIWALSEILRSGKSPDLVSFVQTLC MH GLNDALDSLRKVVPCY K TQKLSKIETLRLAKNYIWALSEILRSGKSPDLVSFVQTLC MH GLNDALESLRKVVPCYSKTQKLSKIETLRLAKNY IWALSEILRSGKSPDLMSFVQALC MHGLN A L A LRKVVPCYSKTQKLSKIETLRLAKNYIWALSEILRSGKSPDLVSFVQTLC

KGLSQPTTNLVAGCLQLNP RTFLPEQNP DNP PHLPTASA SFPVH P SYQSPGLPSP PYGT $K G L S Q P T T N L V A G C L Q L N P R T F L P E Q N P D M P P H L P T A S A S F P V H P Y S Y Q S P G L P S P P Y G T$ KGLSQPTTNLVAGCLQLNPRTFLPEQNPDMP PHLP TASASFP VHPYSYQSPGLPSPPYGT $K G L S Q P T T N L V A G C L Q L N P R T F L P E Q N Q D M P P H L P T A S A S F P V H P Y S Y Q S P G L P S P P Y G T$ KGLSQPTTNLVAGCLQLNPRTFLPEQSADAARHLPPAGAPFAPPPFPYASPGLPSPPYGT KGLSQPTTNLVAGCLQLNPRTFLPEQSQDIQSHMQTASSSFELQGYPYQSPGLPSPPYGT KGLSOPTTNLVAGCLQLNPRTFLPEQSQEMP PHMQTASASESALPY SYQTPGLPSPPYGT KGLSQPTTNLVAGCLQLNPRTFLPEQn-dmpPHIPtAsasFPVhPYsYq 


\section{MmBETA 2 \\ R I B T A 2 \\ C g B ETA 2 \\ H $\triangle$ BETA 2 \\ G g B E T 2 \\ X1BETA 2 \\ D $\triangle B E T A 2$ \\ consensus}

M B B T A 2

R B BETA 2

C gBETA 2

H $\$$ B ETA 2

G $\mathrm{BETA} 2$

X 1 BETA 2

D $\triangle B E T A 2$

consensus

$\begin{array}{lll}\text { MMBETA2 } & 353 & \text { AIFHD- } \\ \text { RABETA2 } & 353 & \text { AIFHD- } \\ \text { CgBETA2 } & 351 & \text { AIFHD- } \\ \text { HSBETA2 } & 352 & \text { AIFHD- } \\ \text { GgBET2 } & 353 & \text { AIFHE- } \\ \text { XIBETA2 } & 348 & \text { AIFHD- } \\ \text { DIBETA2 } & 345 & \text { AIFHDS } \\ \text { COngensus } & 361 & \text { AIFHd - }\end{array}$
361 AIFHd -
234 MDSSHVFH VKPP PHAYSAALEPF FESP - ITDCTSPSFDGPLSP PLSTNGNFSFKHEPSAE 234 MDSSHVFHVKPP PHAYSAALEPFFBSP-LTDCPSPBFDGPLSPPLSTNGNFSFKHEPSTE 233 MDSSHVFQVKPE PHAYSATLEP F FE S - LTDCTSPSF DGPLSP PLSINGNFSFKHEPSAR 234 MDSSHVFHVKPP PHAYSAALEPFFESP-LTDCTSPSFDGPLSP L STNGNFSFKHEPSAE 237 MDSSHLFHLKPP-HAYGAALEPFFEGG-LPEGAGPAFDGPLSPPLSTYGNFSFRHEPAAD 235 MDSSHVFH VKP--HSYGA ALEPFFDSSTVTECTSPSFDGPLSP L SVNGNFTFKHEHS-E 229 MDSSHIFH VKP-- HAYGSALEPFFDTT-LTDCTSPSFDGPLSPPLSVNGNFSFKHEPSSE 241 MDSSHVFhvKPPPHaYsa a LPFFesp-1tdctsPsFDGPLSPPLSinGNFsFREP

293 FEKNYAFTHHYPAAIZA QPQSHGSIFSSGAA A PREIPIDNIMSFDSHSHHERVMSAQLN 293 FEKNYAFTMHYPAATLAQPQSHCSIFSSGAAAPRCEIPIDNIMSFDSHSH ERVMSAQLN 292 FEKNYAFTMHYPAATLA CPQSHCSIFS-CATAPRCEIPIDNIMSFDSHSHHERVMSAQLN 293 FEKNYAFTMHYPAATLACAQSHCSIFS- -TAAPRCEIPIDNIMSFDSHSH ERVMSAQLN 295 FDNSYAFTMHYPAG PLPA PAHAAVF S--GA AARCBLPADGLAPYEGHPH ERVLSAQLS 292 Y DKNYTFTMHYPAA I IS- - QGHGPLFS- - TGGPRCEIPIDTIMSYDGHSH ERVMSAQLN 286 FEKNYAFTMHYQAAGLAGAQGHAASLY - A G TQRCDIPMENIMSYDGHSHHERVMNAQLN 301 feknYaFTMHYpAatlag-qsHgsifs-gaapRCeipidnimsfds

FIG 2. Alignment of BETA2 protein sequences from various species. The bHLH domain is drawn on top of the sequence. The consensus line indicates sequence identity (upper case) and similarity (lower case). Mm, Mus musculus; $\mathrm{Rn}$, Rattus norvegicus; $\mathrm{Cg}$, Cricetinae gen. sp.; $\mathrm{Hs}$, Homo sapiens; $\mathrm{Gg}$, Gallus gallus; $\mathrm{Xl}$, Xenopus laevis; Dr, Danio rerio. Identical and conserved amino acids are boxed in black and light gray, respectively. 
B E T A 2

C gBETA 2

ND 2 / NDRF / NDF 2

MATH $2 / \mathrm{N} \in \mathrm{X} 1$

NGN 1 / NDF 3

MATH 3 / NeuroM

$N G N 3$

NGN 2 / MATH 4

DMATONAL

MATH 1

Beta 3

MIST 1

TWIST/DERMIS 1

PTF1/P48

MASH 1

My०D 1

E 2 A

HES 1

consensus

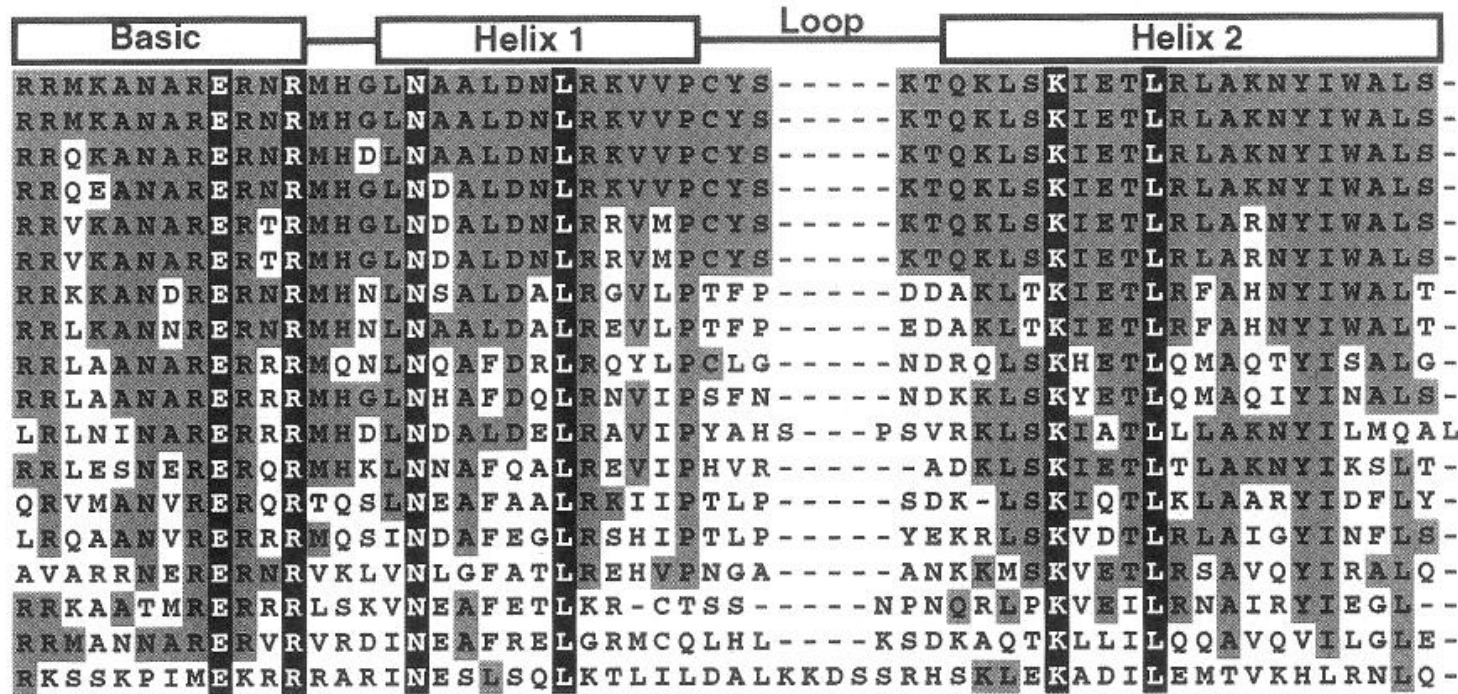

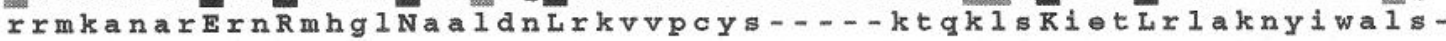

FIG. 3. Sequence comparison of the mouse BETA2 with other bHLH proteins. Unless stated otherwise, only murine sequence were used. The loop sequence of BETA2, ND2/NDRF/NDF2, MATH2/Nex1, and NGN1/NDRF3 is very well conserved, which suggests that they could form a subfamily of bHLH. Identical amino acids to mouse BETA2 are shown in gray, whereas fully conserved amino acids and conserved amino acids are boxed in light gray and black, respectively. Cg, Cricetinae gen. sp.; Dm, Drosophila melanogaster. 


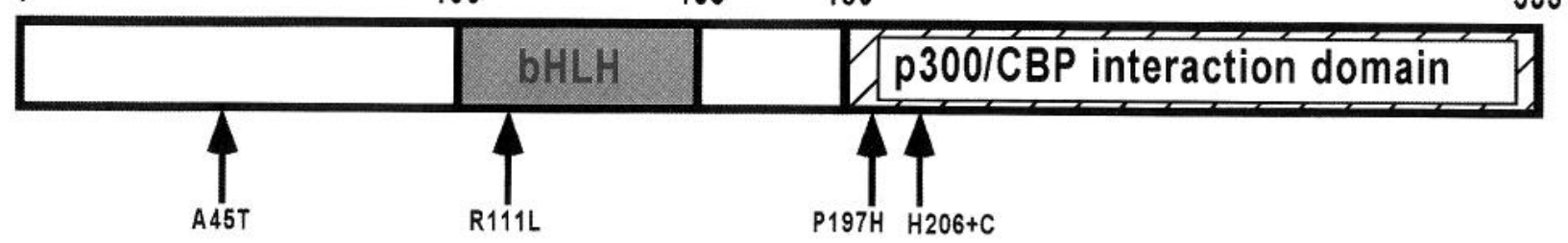

$\begin{array}{rr}189 & 299\end{array}$

$300 \quad$ AD 2

355

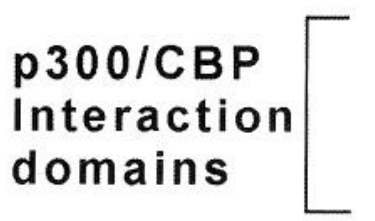

$$
100
$$

\section{5}

155 299 domain

FIG. 4. The BETA2 protein. Schematic representation of the functional domains of hamster BETA2. The bHLH is located between aa 100 and 155 . The p300/CBP-interacting domain is located C-terminal of the bHLH between aa 189 and 355. Two activation domains were identified in the C-terminal from aa 189 to 299 and 300 to 355 . Three p300/CBP interaction domains were characterized. bHLH itself is able to interact with p300; aa 155 to 299 , which overlaps with AD1; and aa 300 to 355 , which corresponds to AD2. Also shown are the four DNA polymorphisms identified and indicated by the arrows and their mutation. 
pattern. The BETA2 gene is expressed very early during pancreas ontogeny. It is detected at $\mathrm{e} 9.5$ in the pancreatic primordia in glucagon-expressing cells, suggesting that BETA2 is expressed in early precursor cells. At e12.5, BETA2 is found in both dorsal and ventral pancreatic buds. By e 14.5, BETA2 is expressed in ductal epithelial cells and in the small population of glucagon-producing cells that are budding from the duct. At e17.5, BETA2 mainly is expressed in small clusters of endocrine cells and rarely in ductal epithelial cells. Such expression pattern suggests a role for BETA2 in the terminal differentiation of endocrine cells, consistent with its proposed role in the terminal differentiation of neurons (see below).

\section{B. BETA2 KNOCKOUT MODEL}

In order to study the role of BETA2 in the pancreas, a mouse knockout model was generated (Naya et al., 1997). Homozygous BETA2 ${ }^{-/}$newborns appear to be malnourished and dehydrated and died within 5 days of birth. Mutant pups are hyperglycemic, when compared to age-matched wild-type or heterozygote littermates; mutants show ketonuria, suggesting severe diabetes. Close examination of homozygous BETA2 null mice indicates a striking reduction in the number of islet cells, especially $\beta$ cells ( 25 percent of the wild type). In addition, analysis of newborn pancreata of mutant mice reveals a drastic reduction of endocrine $\alpha$ cells as well as a failure of residual endocrine cells to aggregatc into mature islets (Naya et al., 1997), suggesting that BETA2 is essential for the morphogenesis of pancreatic islets.

Further examination of embryos indicates that the defect in BETA2 $2^{-/-}$animals occurs after e14.5. Prior to e14.5, the number of BETA2-expressing cells in the developing pancreas is similar between heterozygote and BETA2 ${ }^{-/-}$animals. E14.5 is an important threshold in pancreas development in mice. It marks the beginning of the second wave of endocrine cell differentiation, which is believed to generate the majority of endocrine cells. Thus, in the absence of BETA2, endocrine precursor cells do not massively differentiate and instead undergo programmed cell death. The pancreata of e17.5 null mutants have a profound decrease in endocrine cell numbers and fail to form islets. It is also important to point out that insulin is still expressed in the BETA2 $2^{-/}$pancreas, suggesting the lack of requirement of BETA2 for insulin gene expression. Alternatively, other bHLH proteins, known or novel, could compensate for the lack of BETA2 and play a role in transcription of the insulin gene. Furthermore, transcription factors such as PDXI (which is unaffected by the absence of BETA2) could be sufficient to regulate the insulin gene.

In the transgenic model of overexpression of BETA2 in the pancreas, a moderate increase in endocrine cells is observed in the developing pancreas (Schwitzgebel et al., 2000). This suggests a role of BETA2 in endocrine cell differentiation. A more-severe phenotype is observed when NGN3 is overex- 
pressed in the pancreas (Apelquist et al., 1999; Schwitzgebel et al., 2000). In this case, one observes a hypoplastic pancreas likely due to premature differentiation of endocrine precursor cells. On one hand, the more-severe phenotype of NGN3 overexpression, compared to BETA2 overexpression, suggests that NGN3 is an upstream regulator of BETA2. On the other hand, it indicates that NGN3 is likely to regulate genes other than BETA2. Overall, these results demonstrate that a tight regulation of bHLH expression is required for normal pancreas development.

\section{BETA2 AND DIABETES}

Several transcription factors important for the development and functioning of $\beta$ cells have been identified as the factors responsible for maturity-onset diabetes of the young (MODY). These include the HNF1 $\alpha,-1 \beta$, and $-4 \alpha$ for MODY 1, 3, and 5, respectively, and the homeobox protein PDX1 for MODY4 (Horikawa et al., 1997; Stoffers et al., 1997; Yamagata et al., 1996a,1996b). The BETA2 gene is located on chromosome $2 \mathrm{q} 32$ in humans, a region to which the insulin-dependent diabetes 7 (IDDM7) locus has been assigned (Owerbach et al., 1997). Different groups have identified five DNA polymorphisms at this locus (Table I). The most-common polymorphism is a mutation that results in an alanine-to-threonine conversion at position 45 (A45T) and is linked to type I diabetes in Japanese and Danish populations (Hansen et al., 2000; Iwata et al., 1999) but is not in American and French populations (Dupont et al., 1999; Malecki et al., 1999; Owerbach et al., 1997). Interestingly, two others mutations - arginine 111 to leucine (R111L) in the DNA binding domain and an insertion of a cytosine residue in a poly $\mathrm{C}$ tract at codon 206 (histidine), resulting in a frame shift premature termination at amino acid $242(\mathrm{H} 206+\mathrm{C})$ - have been linked to type 2 diabetes in American population in the heterozygous state (Malecki et al., 1999). The R111L mutation has no DNA binding activity, whereas the $\mathrm{H} 206+\mathrm{C}$ mutation retains its DNA binding ability but is unable to interact with the coactivator $\mathrm{p} 300$. The clinical profile indicates that the $\mathrm{H} 206+\mathrm{C}$ mutation is more severe than the R111L mutation in the heterozygous state. This suggests that the $\mathrm{H} 206+\mathrm{C}$ could be acting in a dominant-negative fashion by interacting with class A bHLH on DNA but is unable to activate transcription of target genes. In contrast, the R111L mutant is unable to interact with DNA but could heterodimerize with class A partner(s) or squelch important co-regulators of the remaining functional BETA2 protein, thus partially affecting the function of the wild-type BETA2.

\section{INTESTINE}

BETA2 also is expressed in all enteroendocrine cells of the diffuse neuroendocrine system of the gut (Rindi et al., 1999). However, in the absence of BETA2, only secretin- and CCK-expressing enteroendocrine cells are absent (Mutoh et al., 
TABLE I

DNA Polymorphisms Identified in the Human BETA2 Coding Region

\begin{tabular}{llll} 
& Polymorphism & Type I & Type II \\
\hline Owerbach et al., 1997 & A45T & No linkage & ND \\
Furuta et al., 1998 & A45T & ND & No linkage \\
Dupont et al., 1999 & A45T & No linkage & No linkage \\
Malecki et al., 1999 & A45T & ND & No linkage \\
& R111L & ND & Yes \\
P197H & ND & No linkage \\
Iwata et al., 1999 & H206+C* & ND & Yes \\
Hensen et al., 1999 & A45T & Yes & No linkage \\
& A45T & Yes & No linkage \\
& P197H & No linkage & No linkage \\
& S259S & No linkage & No linkage
\end{tabular}

The most-common one is an alanine to threonine at codon 45 (A45T), which is present in all the ethnic populations studied. This A45T mutation is linked to type I diabetes in Japanese and Danish populations but not in French or American populations. Two mutations in the BETA2 protein are linked to type II diabetes (R11L and $\mathrm{H} 206+\mathrm{C}$ ) in the heterozygous state (see text for more details). *This mutation results in an insertion of $\mathrm{a} C$ in a $\mathrm{C}$-stretch, which leads to a truncated protein. [See Figure 4 for more details.] ND, not determined.

1998; Naya et al., 1997). All other enteroendocrine hormones (i.e., gastrin inhibitory peptide, substance P, glucagon-like peptides, peptide YY, serotonin, somatostatin) are present. This suggests that BETA2 is a marker for enteroendocrine cells but is only required for the terminal differentiation of secretin- and CCKproducing cells and/or the expression of these genes in enteroendocrine cells. These results concur with the observation that secretin and CCK cells might arise from a common progenitor (Rindi et al., 1999). In addition, the absence of these two pancreatic secretagogues may explain the inability of pancreatic acinar exocrine cells to secrete zymogen granules in BETA2 mutant animals (Naya et al., 1997). Additional transcription factors likely are required for the differentiation of the enteroendocrine cell types observed in the gut epithelium. 


\section{E. BRAIN}

Although this review is not focused on the brain, understanding BETA2 function requires the discussion of its role in neuronal physiology. In general, BETA2 is expressed throughout neuronal development, mostly in terminally differentiating neurons (Lee et al., 1995,2000; Liu et al., 2000b; Naya et al., 1997).

During development, BETA2 is first detected around e8 in neuronal epithelium. At $\mathrm{e} 9.5$, high expression is observed in the developing trigeminal ganglia. At e1 1.5, strong expression is observed in the cranial ganglia ( $\mathrm{V}$ to $\mathrm{XI}$ ), the dorsal root ganglia, and spinal cord. BETA2 is not detected in the mitotically active ventricular zone in the cerebral cortex but rather adjacent to it. BETA2 is also detected in differentiating neurons of the nasal epithelium and the retina. At e14.5, the expression of BETA2 is turned off in cranial ganglia- and dorsal root gangliadifferentiated neurons. This suggests that BETA2 plays a role in the initiation of terminal differentiation of certain neurons. By e18.5, there is a general decrease of BETA2 expression throughout the brain, with the exception of the granule cells in the cerebellum and dentate gyrus, where an increase in expression is observed due to the differentiation of precursor cells into granule cells. In adult mice, BETA2 is expressed in the olfactory bulb, hippocampus, cerebellum, and pituitary gland. This expression is indicative of another function of BETA2 in fully differentiated neurons.

As mentioned previously, BETA2 null mutants are not viable in a mixed C57B6/129SvEv background but when they are crossed into a pure $129 \mathrm{SvJ}$ background, approximately 40-65 percent of the mutant animals survive (Liu et al., 2000a). This possibly is due to the presence of a modifier gene related to BETA2. The rescue of the BETA2 null mutant allowed our group to study the role of BETA2 in postnatal neuronal development, especially granule cells of the dentate gyrus and cerebellum (Liu et al., 2000a).

\section{F. DENTATE GYRUS}

In the hippocampus, BETA2 is expressed in the Ammon's horn and granule cells of the dentate gyrus in adult mice. Granule cells are generated in two phases during dentate gyrus development. The first phase occurs during embryogenesis, when granule cells appear at the ventricular surface of the neuroepithelium and migrate in conjunction with the precursor cells to the dentate anlage. The second wave of granule cells that will account for the majority of the hippocampus granule cells is generated postnatally from precursor cells that migrate from the ventricular zone to the dentate anlage. Interestingly, in addition to differentiated granule cells, BETA2 expression was observed in a few mitotic cells of the dentate gyrus as revealed by BrdU labeling (Lee et al., 2000; Liu et al., 2000a; Miyata et al., 1999). The presence of BETA2 in BrdU-positive cells could be explained by 
their recent exit from the cell cycle and an early onset of BETA2 expression. In the absence of BETA2, granule and progenitor cells are decreased such that the later events in development of the dentate gyrus is greatly affected. BETA2 may be required for the specification of an early subpopulation of granule cells that then organizes the dentate granule cell layer and regulates birth of additional granule cells, independent of continued BETA2 function. Thus, the role of BETA2 in the dentate gyrus appears complex, involving the maintenance or survival of precursor cells and the terminal differentiation of granule cells.

\section{G. CEREBELLUM}

As in the dentate gyrus, there is a defect in granule cells in the cerebellum. This is not surprising, since the granule cells of the cerebellum share similar developmental characteristics with those of the dentate gyrus (Altman, 1967). During development, BETA2 is expressed in the inner layer of the external granular layer (EGL), where postmitotic cells are located. Beginning at birth, granule cell precursors proliferate and differentiate into granule cells. As in the hippocampus, BETA2 is detected in both mitotic and postmitotic cells of the EGL in the postnatal cerebellum. Additionally, BETA2 is required for terminal differentiation of granule cells, since its absence leads to a decrease in granule cell number (M. Liu and M.J. Tsai, personal observations; Miyata et al., 1999). The effect is more severe in the posterior lobules ( $\mathrm{V}$ to XI) than in the anterior lobules of the cerebellum. The presence of surviving granule cells suggests a possible compensatory mechanism by other bHLHs, such as NeuroD2 or Nex 1/Math2, that also are expressed in the cerebellum. We are currently studying the mechanism of the differential depletion of granule cells that occurs between the anterior and posterior cerebellum.

\section{H. RETINA}

In adult mice, BETA2 expression is detected in the outer nuclear layer of the central retina and in all layers (i.e., outer and inner) of the more-peripheral retina (M. Liu and M.J. Tsai, personal observations; Morrow et al., 1999). In the retina, BETA2 likely plays a role in glial vs. neuronal cell fate determination. In the absence of BETA2, one observes an increase in Müller glial cells (Morrow et al., 1999). In a gain-of-function experiment, overexpression of BETA2 in postnatal retina resulted in a complete blockade of Müller glial cell development. In addition, BETA2 plays a role in interneuron development, determining the ratio between amacrine and bipolar neurons (Morrow et al., 1999). Finally, BETA2 is implicated in the survival of a subset of rod photoreceptor cells (Morrow et al., 1999). These recent findings broaden our view of BETA2 function and suggest that it can have an active role in cell fate determination. 


\section{IN VITRO}

In vitro, BETA2 can induce terminal differentiation of cell lines (P19, PC12, and F11) when transfected (Cho et al., 2000; Farah et al., 2000; Noma et al., 1999). When a mutant of BETA2 lacking the C-terminal activation domain is introduced in F11 neuroblastoma cells, differentiation induced by cAMP is inhibited (Cho et al., 2000). This implies that this truncated molecule harbors a dominant-negative function. BETA2 also can induce transdifferentiation of retinal pigment epithelium into cells that resembles young photoreceptors (Yan and Wang, 2000a,2000b). Furthermore, using retina explant cultures derived from rat or mouse, it was shown that BETA2 plays multiple functions in cell fate determination and differentiation as well as survival of various retinal cell types (Morrow et al., 1999). Overall, the role of BETA2 in neuronal development appears complex and dependent on the system being studied. These results also implicate BETA2 in cell fate determination, differentiation, and neuronal survival.

\section{Regulation of BETA2}

BETA2 expression pattern and timing indicate that it plays important functions in differentiation. NGN1 expression spatially overlaps and temporally precedes that of BETA2 during neuronal development (Fode et al., 1998; Ma et al, 1998,1999; Sommer et al., 1996). In addition, ectopic overexpression of NGN1 induces BETA2 gene expression and neurogenesis in Xenopus ectoderm (Ma et al., 1996; Perron et al., 1999). In order to analyze further the regulation of BETA2 expression, we have cloned the murine BETA2 promoter and shown its regulation by bHLH proteins in transient transfection assays (Huang et al., 2000). NGN3 was shown to stimulate the activity of the BETA2 promoter in HIT, $\beta$-TC, and Hela cells. NGN3 and BETA2 expression patterns also partially overlap in the developing pancreas, suggesting that the regulation observed in vitro might exist in vivo (I luang et al., 2000). Indeed, injection of NGN3 mRNA into Xenopus embryo causes ectopic expression of BETA2 in the trunk and an abnormal expansion of its expression in the head region (Huang et al., 2000). The neurogenin family of transcription factors generally is regarded as playing roles in neuronal determination. The NGN1 and NGN2 genes are important in the determination of selected neurons; their absence has revealed a block at the earliest stages of neurogenesis in complementary sets of cranial sensory ganglia (Fode et al., 1998,2000; Ma et al., 1998,1999).

Alignment of the mouse and human BETA2 promoters reveals strong conservation of the two promoters over about two kilobases. The first $400 \mathrm{bp}$ of the promoters are particularly well conserved. Within this region, three E-boxes and two $\mathrm{Spl}$ sites were identified as putative DNA response elements (Huang $e t$ al., 2000; Miyachi et al., 1999; Yoon et al., 1998). Promoter deletion analysis has 
revealed the presence of a proximal DNA element required for basal activity in BETA2-expressing cells such as $\beta$-TC, HIT, and $\beta$-HC3 (Huang et al., 2000; Miyachi et al., 1999; Yoon et al., 1998). Deletion of the three proximal E-boxes greatly affects basal promoter activity, suggesting a potential role for a $\mathrm{bHLH}$ protein in the regulation of BETA2 (Huang et al., 2000). In transient transfection assays, NGN3 and BETA2 upregulate a BETA2 promoler-luciferase construct (Huang et al., 2000). While the regulation of BETA2 by NGN3 observed in transient transfection assays is likely to be of physiological importance, the autoregulation of the BETA2 gene and its importance for developing and adult islets is less clear. This awaits the generation of a tissue-specific knockout of the BETA2 locus in islet cells. Finally, a more-detailed analysis of the BETA2 promoter is required for a full understanding of the regulation of the tissue-specific expression of the BETA2 gene.

\section{Summary}

The development of the pancreas is a very complex process. The discovery of transcription factors is a first step toward a better understanding of the genetic program responsible for the activation or repression of the genes necessary for the developmental process. In turn, the identification of the genes targeted by these transcription factors (e.g., other transcription factors, growth factors and their receptors, extracellular matrix components, modifying proteins, signaling molecules) will broaden our views of pancreatic development and diabetes. In this regard, we believe that the BETA2 knockout mouse is an attractive and interesting model for the identification of important regulators of endocrine cell development.

From the analysis of the BETA2 knockout mouse, it was shown that BETA2 is needed for the proper formation of pancreatic islets. Its expression pattern and functional analysis assigns to BETA2 a key role in the terminal differentiation of pancreatic endocrine cells. In its absence, endocrine cells are decreased in number due to increase in programmed cell death and a failure of these cells to aggregate into islets.

BETA2 also is expressed in various regions of the central nervous system. There, BETA2 is similarly involved in terminal differentiation of granule cells of the dentate gyrus and cerebellum. In addition to its established role in differentiation, BETA2 appears to play a role in maintenance and survival of granule cell progenitors in these structures and in cell fate determination in the retina. The expression of BETA2 in adult neuronal and pancreatic endocrine tissues suggests a role different from the differentiation function played during development. Interestingly, BETA2 expression decreases with age in the hippocampus but not in the cerebellum in adult mice (Uittenbogaard and Chiaramello, 2000). The significance of this age-related downregulation is unknown but may contribute to 
neurodegenerative diseases in the elderly. Finally, we have recent evidence for an additional role for BETA2 in ear development (Liu et al., 2000b). The observed phenotype has been attributed to defects in the delamination of the cochlear-vestibular ganglion neurons and in the differentiation and patterning of the sensory cochlear epithelium. Finally, it would be interesting to evaluate whether the BETA2 mutations that have been linked to diabetes in some populations (Hansen et al., 2000; Iwata et al., 1999; Malecki et al., 1999) affect other aspects of BETA2 physiology, including the development and functions of the hippocampus, cerebellum, retina, and ear, which might be associated with behavioral or perceptional deficits (Liu et al., 2000a,2000b; Miyata et al., 1999).

\section{ACKNOWLEDGMENTS}

The authors gratefully acknowledge helpful discussions with Dr. Debra Bramblett during the preparation of the manuscript. M.-.J.I. is supported by a grant from the National Institutes of Health (DK55325). E. N-.G. is a recipient of a postdoctoral fellowship from the Juvenile Diabetes Foundation International.

\section{REFERENCES}

Ahlgren, U., Jonsson, J., and Edlund, H. (1996). Development 122, 1409-1416.

Ahlgren, U., Pfaff, S.L., Jessell, T.M., Edlund, T., and Edlund, H. (1997). Nature 385, 257-260.

Ahlgren, U., Jonsson, J., Jonsson, L., Simu, K., and Edlund, H. (1998). Genes Dev. 12, 1763-1768.

Altman, J. (1967). In "The Neurosciences" (G.C. Quarton, T. Melnechuk, and F.O. Schmitt, eds.), pp. 723-743. The Rockefeller University Press, New York.

Ang, S.L., and Rossant, J. (1994). Cell 78, 561-574.

Apelqvist, A., Li, H., Sommer, L., Beatus, P., Anderson, D.J., Honjo, T., Hrabe de Angelis, M., Lendahl, U., and Edlund, H. (1999). Nature 400, 877-881.

Blackwell, T.K., and Weintraub, H. (1990). Science 250, 1104-1110.

Blackwell, T.K., Huang, J., Ma, A., Kretzner, L., Alt, F.W., Eisenman, R.N., and Weintraub, H. (1993). Mol. Cell. Biol. 13, 5216-5224.

Bramblett, D.E., Huang, H.P., and Tsai, M.J. (2000). Adv. Pharmacol. 47, 255-315.

Cho, J.-H., Kwon, I.-S., Ghil, S.-H., Tsai, M.-J., Kim, Y.-S., Lee, Y.-D., and Suh-Kin, H, submitted.

Crowe, D.T, and Tsai, M.J. (1989). Mol. Cell. Biol. 9, 1784-1789.

Crowe, D.T., Hwung, Y.P., Tsai, S.Y., and Tsai, M.J. (1988). Prog. Clin. Biol. Res. 284, 211-224.

Dupont, S., Dina, C., Hani, E.H., and Froguel, P. (1999). Diabetes Metab. 25, 516-517.

Edlund, H. (1998). Diabetes 47, 1817-1823.

Edlund, H. (1999). Curr. Opin. Cell Biol. 11, 663-668.

Ellenberger, T., Fass, D., Amaud, M., and Harrison, S.C. (1994). Genes Dev. 8, 970-980.

Farah, M.H., Olson, J.M., Sucic, H.B., Hume, R.I., Tapscott, S.J., and Turner, D.L. (2000). Development 127, 693-702.

Ferre-D'Amare, A.R., Prendergast, G.C., Ziff, E.B., and Burley, S.K. (1993). Nature 363, 38-45.

Ferre-D'Amare, A.R., Pognonec, P., Roeder, R.G., and Burley, S.K. (1994). EMBO J. 13, 180-189.

Fode, C., Gradwohl, G., Morin, X., Dierich, A., LeMeur, M., Goridis, C., and Guillemot, F. (1998). Neuron 20, 483-494.

Fode, C., Ma, Q., Casarosa, S., Ang, S.L., Anderson, D. J., and Guillemot, F. (2000). Genes Dev. 14, 67-80. 
Gannon, M., Ray, M.K., Van Zee, K., Rausa, F., Costa, R.H., and Wright, C.V. (2000). Development 127, 2883-2895.

Glick, E., Leshkowitz, D., and Walker, M.D. (2000). J. Biol. Chem. 275, 2199-2204.

Gradwohl, G., Dierich, A., LeMeur, M., and Guillemot, F. (2000). Proc. Natl. Acad Sici. U.S.A. 97, 1607-1611.

Grapin-Botton, A., and Melton, D.A. (2000). Trends Genet. 16, 124-130.

Guillemot, F. (1999). Exp. Cell Res. 253, 357-364.

Guz, Y., Montminy, M.R., Stein, R., Leonard, J., Gamer, L.W., Wright, C.V., and Teitelman, G. (1995) Development 121, 11-18.

Hansen, L., Jensen, J.N., Urioste, S., Petersen, H.V., Pociot, F., Eiberg, H., Kristiansen, O.P., Hansen, T., Serup, P., Nerup, J., and Pedersen, O. (2000). Diabetes 49, 876-878.

Harrison, K.A., Thaler, J., Pfaff, S.L., Gu, H., and Kehrl, J.H. (1999). Nature Genet. 23, 71-75.

Horikawa, Y., Iwasaki, N., Hara, M., Furuta, H., Hinokio, Y., Cockburn, B.N., Lindner, T., Yamagata, K., Ogata, M., Tomonaga, O., Kuroki, H., Kasahara, T., Iwamoto, Y., and Bell, G.I. (1997). Nature Genet. 17, 384-385.

Huang, H.P., Liu, M., El-Hodiri, H.M., Chu, K., Jamrich, M., and Tsai, M.J. (2000). Mol. Cell. Biol. 20, 3292-3307.

Hwung, Y.P., Gu, Y.Z., and Tsai, M.J. (1990). Mol. Cell. Biol. 10, 1784-1788.

Ishibashi, M., Ang, S.L., Shiota, K., Nakanishi, S., Kageyama, R., and Guillemot, F. (1995). Genes Dev. 9, 3136-3148.

Iwata, I., Nagafuchi, S., Nakashima, H., Kondo, S., Koga, T., Yokogawa, Y., Akashi, T., Shibuya, T., Umeno, Y., Okeda, T., Shibata, S., Kono, S., Yasunami, M., Ohkubo, H., and Niho, Y. (1999). Diabetes 48, 416-419.

Jacquemin, P., Durviaux, S.M., Jensen, J., Godfraind, C., Gradwohl, G., Guillemot, F., Madsen, O.D., Carmeliet, P., Dewerchin, M., Collen, D., Rousseau, G.G., and Lemaigre, F.P. (2000). Mol. Cell. Biol. 20, 4445-4454.

Jarriault, S., Brou, C., Logeat, F., Schroeter, E.H., Kopan, R., and Israel, A. (1995). Nature 377, 355-358.

Jarriault, S., Le Bail, O., Hirsinger, E., Pourquie, O., Logeat, F., Strong, C.F., Brou, C., Seidah, N.G., and Isra I, A. (1998). Mol. Cell. Biol. 18, 7423-7431.

Jensen, J., Heller, R.S., Funder-Nielsen, T., Pedersen, E.E., Lindsell, C., Weinmaster, G., Madsen, O.D., and Serup, P. (2000a). Diabetes 49, 163-176.

Jensen, J., Pedersen, E.E., Galante, P., Hald, J., Heller, R.S., Ishibashi, M., Kageyama, R., Guillemot, F., Serup, P., and Madsen, O.D. (2000b). Nature Genet. 24, 36-44.

Jonsson, J., Carlsson, L., Edlund, T., and Edlund, H. (1994). Nature 371, 606-609.

Jonsson, J., Ahlgren, U., Edlund, T., and Edlund, H. (1995). Intl. J. Dev. Biol. 39, 789-798.

Kaestner, K.H., Katz, J., Liu, Y., Drucker, D.J., and Schutz, G. (1999). Genes Dev. 13, 495-504.

Kim, S.K., Hebrok, M., and Melton, D.A. (1997). Cold Spring Harb. Symp. Quant. Biol. 62, 377-383.

Krapp, A., Knofler, M., Ledermann, B., Burki, K., Berney, C., Zoerkler, N., Hagenbuchle, O., and Wellauer, P.K. (1998). Genes Dev. 12, 3752-3763.

Lammert, E., Brown, J., and Melton, D.A. (2000). Mech. Dev. 94, 199-203.

Lee, J.E., Hollenberg, S.M., Snider, L., Turner, D.L., Lipnick, N., and Weintraub, H. (1995). Science 268, 836-844.

Lee, J.K., Cho, J.H., Hwang, W.S., Lee, Y.D., Reu, D.S., and Suh-Kim, H. (2000). Dev. Dynam. 217, 361-367.

Leonard, J., Peers, B., Johnson, T., Ferreri, K., Lee, S., and Montminy, M.R. (1993). Mol. Endocrinol. 7, 1275-1283.

Li, H., Arber, S., Jessell, T.M., and Edlund, H. (1999). Nature Genet. 23, 67-70.

Liu, M., Pleasure, S.J., Collins, A.E., Noebels, J.L., Naya, F.J., Tsai, M.J., and Lowenstein, D.H. (2000a). Proc. Natl. Acad. Sci. U.S.A. 97, 865-870. 
Liu, M., Pereira, F.A., Price, S.D., Chu, M.J., Shope, C., Himes, D., Eatock, R.A., Brownell, W.E., Lysakowski, A., and Tsai, M.-J. (2000b). Genes Dev. 14, 2839-2854.

Ma, P.C., Rould, M.A., Weintraub, H., and Pabo, C.O. (1994). Cell 77, 451-459.

Ma, Q., Kintner, C., and Anderson, D.J. (1996). Cell 87, 43-52.

Ma, Q., Chen, Z., del Barco Barrantes, I., de la Pompa, J.L., and Anderson, D.J. (1998). Neuron 20, 469-482.

Ma, Q., Fode, C., Guillemot, F., and Anderson, D.J. (1999). Genes Dev. 13, 1717-1728.

Malecki, M.T., Jhala, U.S., Antonellis, A., Fields, L., Doria, A., Orban, T., Saad, M., Warram, J.H., Montminy, M., and Krolewski, A.S. (1999). Nature Genet. 23, 323-328.

Miller, C.P., McGehee, R.E., Jr., and Habener, J.F. (1994). EMBO J. 13, 1145-1156.

Miyachi, T., Maruyama, H., Kitamura, T., Nakamura, S., and Kawakami, H. (1999). Brain Res. Mol. Brain Res. 69, 223-231.

Miyata, T., Maeda, T., and Lee, J.E. (1999). Genes Dev. 13, 1647-1652.

Morrow, E.M., Furukawa, T., Lee, J.E., and Cepko, C.L. (1999). Development 126, 23-36.

Murre, C., McCaw, P.S., and Baltimore, D. (1989a). Cell 56, 777-783.

Murre, C., McCaw, P.S., Vaessin, H., Caudy, M., Jan, L.Y., Jan, Y.N., Cabrera, C.V., Buskin, J.N., Hauschka, S.D., Lassar, A.B., et al. (1989b). Cell 58, 537-544.

Mutoh, H., Naya, F.J., Tsai, M.J., and Leiter, A.B. (1998). Genes Dev. 12, 820-830.

Naya, F.J., Stellirecht, C.M., and Tsai, M.J. (1995). Genes Dev. 9, 1009-1019.

Naya, F.J., Huang, H.P., Qiu, Y., Mutoh, H., DeMayo, F.J., Leiter, A.B., and Tsai, M.J. (1997). Genes Dev. 11, 2323-2334.

Noma, T., Yoon, Y.S., and Nakazawa, A. (1999). Brain Res. Mol. Brain Res. 67, 53-63.

Offield, M.F., Jetton, T.L., Labosky, P.A., Ray, M., Stein, R.W., Magnuson, M.A., Hogan, B.L., and Wright, C.V. (1996). Development 122, 983-995.

Ohneda, K., Mirmira, R.G., Wang, J., Johnson, J.D., and German, M.S. (2000). Mol. Cell. Biol. 20, 900-911

Owerbach, D., Naya, F.J., Tsai, M.J., Allander, S.V., Powell, D.R., and Gabbay, K.H. (1997). Diabetes 46, 1069-1074.

Perez, S.E., Rebelo, S., and Anderson, D.J. (1999). Development 126, 1715-1728.

Perron, M., Opdecamp, K., Butler, K., Harris, W.A., and Bellefroid, E.J. (1999). Proc. Natl. Acad. Sci. U.S.A. 96, 14996-15001.

Peshavaria, M., Gamer, L., Henderson, E., Teitelman, G., Wright, C.V., and Stein, R. (1994). Mol. Endocrinol. 8, 806-816.

Pictet, R.L., Clark, W.R., Williams, R.H., and Rutter, W.J. (1972). Dev. Biol. 29, 436-467.

Poulin, G., Lebel, M., Chamberland, M., Paradis, F.W., and Drouin, J. (2000). Mol. Cell. Biol. 20, 4826-4837.

Puri, P.L., Sartorelli, V., Yang, X.J., Hamamori, Y., Ogryzko, V.V., Howard, B.H., Kedes, L., Wang, J.Y., Graessmann, A., Nakatani, Y., and Levrero, M. (1997). Mol. Cell 1, 35-45.

Qiu, Y., Sharma, A., and Stein, R. (1998). Mol. Cell. Biol. 18, 2957-2964

Rindi, G., Ratineau, C., Ronco, A., Candusso, M.E., Tsai, M., and Leiter, A.B. (1999). Development 126, 4149-4156.

Robinson, G.L., Peshavaria, M., Henderson, E., Shieh, S.Y., Tsai, M.J., Teitelman, G., and Stein, R. (1994). J. Biol. Chem. 269, 2452-2460.

Sartorelli, V., Puri, P.L., Hamamori, Y., Ogryzko, V., Chung, G., Nakatani, Y., Wang, J. Y., and Kedes, L. (1999). Mol. Cell 4, 725-734.

Schwitzgebel, V.M., Scheel, D.W., Conners, J.R., Kalamaras, J., Lee, J.E., Anderson, D.J., Sussel, L., Johnson, J.D., and German, M.S. (2000). Development 127, 3533-3542.

Serup, P., Petersen, H.V., Pedersen, E.E., Edlund, H., Leonard, J., Petersen, J.S., Larsson, L.I., and Madsen, O.D. (1995). Biochem. J. 310, 997-1003. 
Sharma, A., Moore, M., Marcora, E., Lee, J.E., Qiu, Y., Samaras, S., and Stein, R. (1999). Mol. Cell. Biol. 19, 704-713.

Shieh, S.Y., and Tsai, M.J. (1991). J. Biol. Chem. 266, 16708-16714.

Slack, J.M. (1995). Development 121, 1569-1580.

Sommer, L., Ma, Q., and Anderson, D.J. (1996). Mol. Cell. Neurosci. 8, 221-241.

Sosa-Pineda, B., Chowdhury, K., Torres, M., Oliver, G., and Gruss, P. (1997). Nature 386, 399-402.

St-Onge, L., Sosa-Pineda, B., Chowdhury, K., Mansouri, A., and Gruss, P. (1997). Nature 387, 406-409.

Stoffers, D.A., Ferrer, J., Clarke, W.L., and Habener, J.F. (1997). Nature Genet. 17, 138-139.

Stoffers, D.A., Heller, R.S., Miller, C.P., and Habener, J.F. (1999). Endocrinology 140, 5374-5381.

Uittenbogaard, M., and Chiaramello, A. (2000). Neurosci. Lett. 280, 95-98.

Voronova, A., and Baltimore, D. (1990). Proc. Natl. Acad. Sci. U.S.A. 87, 4722-4726.

Weinstein, D.C., Ruiz i Altaba, A., Chen, W.S., Hoodless, P., Prezioso, V.R., Jessell, T.M., and Darnell, J.E., Jr. (1994). Cell 78, 575-588.

Wells, J.M., and Melton, D. A. (1999). Annu. Rev. Cell. Dev. Biol. 15, 393-410.

Yamagata, K., Furuta, H., Oda, N., Kaisaki, P.J., Menzel, S., Cox, N.J., Fajans, S.S., Signorini, S., Stoffel, M., and Bell, G.I. (1996a). Nature 384, 458-460.

Yamagata, K., Oda, N., Kaisaki, P.J., Menzel, S., Furuta, H., Vaxillaire, M., Southam, L., Cox, R.D., Lathrop, G.M., Boriraj, V.V., Chen, X., Cox, N.J., Oda, Y., Yano, H., Le Beau, M.M., Yamada, S., Nishigori, H., Takeda, J., Fajans, S.S., Hattersley, A.T., Iwasaki, N., Hansen, T., Pedersen, O., Polonsky, K.S., Bell, G.I., et al. (1996b). Nature 384, 455-458.

Yan, R.T., and Wang, S.Z. (2000a). Vis. Neurosci. 17, 157-164.

Yan, R.T., and Wang, S.Z. (2000b). Neurosci. Lett. 280, 83-86.

Yoon, Y.S., Noma, T., Yamashiro, Y., Ito, H., and Nakazawa, A. (1998). Neurosci. Lett. 251, 17-20. 